\title{
Theoretical performance analysis of jute fiber rope bank as media in evaporative coolers
}

\author{
R. K. Kulkarni and S. P. S. Rajput \\ Dept. of Mechanical Engineering, Maulana Azad National Institute of Technology, Bhopal, MP-462 051, India. \\ rkk288in@gmail.com; spsrajput@gmail.com
}

\begin{abstract}
This paper analyzes the performance of jute fiber ropes that are used in the form of rope bank as wetted media in evaporative coolers. Widely spaced and compact arrangements of rope bank are taken into consideration. An ambient condition of $39.9^{\circ} \mathrm{C}$ and $32.8 \% \mathrm{RH}$ is selected on the basis of weather data of Bhopal (2008) India particularly of weather in summer season. For the purpose of this study, the surface temperature of ropes is assumed as WBT of incoming air and theory of simultaneous heat and mass transfer is applied. Saturation efficiency, outlet temperature of air and cooling capacity are calculated for air mass flow rate of $0.9 \mathrm{~kg} / \mathrm{s}$ to $0.3 \mathrm{~kg} / \mathrm{s}$. The saturation efficiency varies between $57 \%$ and $73 \%$ for widely spaced bank and between $74 \%$ and $87 \%$ for compact bank. Outlet temperature of air is determined on the basis of empirical correlation and is found to be in the range of $31.7^{\circ} \mathrm{C}-29.4^{\circ} \mathrm{C}$ and $29.4^{\circ} \mathrm{C}-27.4^{\circ} \mathrm{C}$ for widely spaced bank and compact bank respectively. The cooling capacity varies from $11243 \mathrm{~kJ} / \mathrm{h}-26381 \mathrm{~kJ} / \mathrm{h}$ and from $13384 \mathrm{~kJ} / \mathrm{h}-33852 \mathrm{~kJ} / \mathrm{h}$ for widely spaced bank and compact bank respectively. Fan power increases from 4.7 $\mathrm{W}-104.2 \mathrm{~W}$ and from $16.4 \mathrm{~W}-323.9 \mathrm{~W}$ for widely spaced and compact arrangement respectively. Variation of these parameters with mass flow of air is shown. It is seen that compact arrangement of ropes gives better performance although at the cost of high power consumption.
\end{abstract}

Keywords: Evaporative cooler, saturation efficiency, jute fiber, rope bank.

\section{Nomenclature}

$A_{w}$ : Total wetted surface area of the rope bank $\left(\mathrm{m}^{2}\right) ; C_{p}$ : Specific heat of air $(\mathrm{J} / \mathrm{kgK}) ; D$. Diameter of jute ropes $(\mathrm{m}) ; D_{A B}$ : Diffusion coefficient of water into air $\left(\mathrm{m}^{2} / \mathrm{s}\right)\left(D_{A B}\right)_{s}$ : Diffusion coefficient of water into air at $T s\left(\mathrm{~m}^{2} / \mathrm{s}\right) ; t_{1}$ Dry bulb temperature of ambient air $\left({ }^{0} \mathrm{C}\right) ; t_{2}$ : Dry bulb temperature of outlet air $\left({ }^{0} \mathrm{C}\right) ; H$ : Height of the frame $(\mathrm{m}) ; h_{c}$ : Convective heat transfer coefficient $\left(\mathrm{W} / \mathrm{m}^{2} \mathrm{~K}\right) ; h_{m}$ : Mass transfer coefficient (m/s); $L e$ : Lewis number dimensionless $M_{a}$ : Mass flow rate of air through the rope bank $(\mathrm{kg} / \mathrm{s}) ; N$ : Total number of ropes in bank; $N_{\llcorner}$: Number of rows depth of rope bank; $N u$ : Nusselt number, dimensionless; $P$ : Power required by fan $(\mathrm{W}) ; \operatorname{Pr}$. Prandtl number, dimensionless; $Q_{C}:$ Cooling capacity $(\mathrm{kJ} / \mathrm{h}) ; R_{e_{D m a x}}$ Reynolds number based on maximum velocity of air, dimensionless; $R H$ : Relative humidity of air (\%); $S c$. Schmidt number, dimensionless; $(S c)_{s}$ : Schmidt number at $t_{s}$, dimensionless; $S h_{D}$ : Sherwood number based on diameter of ropes, dimensionless; $S h_{D N L=12}$ : Sherwood number corrected for 12 rows depth, dimensionless; $S D$. Diagonal pitch of rope bank $(\mathrm{m}) ; S L$ : Longitudinal pitch of rope bank (m); $S T$ : Transverse pitch of rope bank $(\mathrm{m}) ; t_{f}$ : Film temperature $\left({ }^{0} \mathrm{C}\right) ; t_{s}$ : Surface temperature of ropes $\left({ }^{0} \mathrm{C}\right) ; V_{a}$ : Velocity of air at the entry to rope bank $(\mathrm{m} / \mathrm{s}) ; V_{\text {max }}$ : Maximum velocity of air through the rope bank $\mathrm{m} / \mathrm{s} ; V_{f}:$ Volume flow rate of air $\left(\mathrm{m}^{3} / \mathrm{s}\right) ; W$ : Width of the frame $(\mathrm{m}) ; t_{w 1}$ : Wet bulb temperature of ambient air $\left({ }^{0} \mathrm{C}\right) ; \Delta P \quad$ : Pressure drop across the rope bank $(\mathrm{Pa}): f$ : Friction factor.

Greek letters

$\omega_{o}:$ Specific humidity of outlet air $(\mathrm{kg} / \mathrm{kg} \mathrm{da}) ; v:$ Kinematic viscosity of air $\left(\mathrm{m}^{2} / \mathrm{s}\right) ; v_{s}:$ Kinematic viscosity of air, at $T s\left(\mathrm{~m}^{2} / \mathrm{s}\right)$;

$\alpha$ : Thermal diffusivity of air $\left(\mathrm{m}^{2} / \mathrm{s}\right) ; \chi$ : Correction factor for pressure drop; $\rho$ : Density of air $\left(\mathrm{kg} / \mathrm{m}^{3}\right) ; \eta$ : Saturation efficiency (\%).

Abbreviations

DBT: Dry bulb temperature $\left({ }^{\circ} \mathrm{C}\right)$; $\mathrm{DBT}_{\max }$ : Maximum dry bulb temperature $\left({ }^{\circ} \mathrm{C}\right)$; RH: Relative humidity $(\%)$; WBT; Wet bulb temperature $\left({ }^{0} \mathrm{C}\right)$.

Introduction

Conventional air conditioning system requires high capital investment and its operating costs often become exponentially high due to its consumption of electricity. Furthermore, the restrictions imposed by protocols limit the type of refrigerants that can be used in these systems. In contrast evaporative cooling systems provide considerably large energy savings when compared with conventional air conditioning systems. Thus, a combined use of conventional and evaporative cooling systems can help achieve lower energy consumption which is not possible if stand alone conventional cooling system was to be used. Evaporative cooling system uses water which causes no harm to environment and it can be fabricated easily. Therefore, this method is used for comfort cooling, livestock housing and storage of fruits, vegetables and horticultural produce.

Evaporative cooling uses a wetted pad through which air is passed at uniform rate to make it saturated. Pads that offer a large air-water contact surface area to aid evaporation of water can be kept in wet state by dripping water on upper surface with the help of a recirculating pump. Water evaporates and in the process air looses a part or all of its sensible heat and gains equivalent amount of latent heat of water vapor thereby leading to decrease in its temperature and increase in humidity. More the amount of evaporation, greater is the cooling effect. Thus, the system is more efficient in hot and dry climates that is, when it is most needed.

However evaporative coolers do not accurately control temperature and humidity and their performance
Research article

CIndian Society for Education and Environment (iSee)
"Jute for air-conditioning" http://www.indjst.org
Kulkarni \& Rajput Indian J.Sci.Technol. 
depends on outside air condition. Moreover, humidity of air also increases during the process. The common material used as wetted media for these coolers is aspen or rigid cellulose. Many researchers have endeavored to improve the performance of these systems by implementing appropriate changes in design, process and materials. Al-Sulaiman (2002) designed a test set-up to evaluate the performance of jute, date palm and luffa fibers as wetted media. His findings showed that jute has highest cooling efficiency followed by luffa and date palm. Salt deposition was the least for jute; however it had poor resistance to mold forming. There was difficulty in keeping the jute fibers uniformly distributed after wetting and therefore he recommended the treatment of jute fibers to get higher mold resistance.

Camrago et al. (2004) developed a mathematical model of direct evaporative cooler and presented their experimental results with rigid cellulose media having area density of $370 \mathrm{~m}^{2} / \mathrm{m}^{3}$. The performance was measured by saturation effectiveness derived in terms of heat transfer coefficient, air mass flow rate, wetted surface area of cooling media and humid specific heat.

Gomez et al. (2005) constructed a test bed set up in order to carry out trials on ceramic evaporative cooling system. Two independent air flows namely return and outdoor were separated by ceramic pipes kept wet by constant water flow on their inner side. Their findings concluded that heat and mass transfer occurred between air flows as a result of the behavior of porous solid and the process is semi-indirect. Porous material acts as a filter and avoids any contamination that can be caused by outside air.

Liao and Chiu (2002) developed a wind tunnel technique for measuring performance of the pad. They used coarse fabric and fine fabric PVC sponge mesh as wetted media. The fan pad system was simulated on the basis of measurements of air velocity, dry and wet bulb temperatures and pressure drop. The correlations for heat and mass transfer coefficients were formulated for two pad materials.

Maheshwari et al. (2001) conducted an analytical evaluation of the performance of indirect evaporative cooling unit and undertook a comparative study on the power requirements of conventional packaged air conditioner and indirect cooling unit. The comparison was made on the basis of measures arrived after calculating relevant cooling capacity. Simultaneous heat and mass transfer from surface of cylinders or tube banks has also been analyzed by different authors. Khan et al. (2006) carried out an analytical investigation of heat transfer from tube banks and presented simplified models of heat transfer for in-line and staggered arrangement. They concluded that compact banks and staggered arrangement gives higher heat transfer rates when compared to widely spaced and in-line arrangement.

Sun and Marrero (1996) performed theoretical as well as experimental studies on heat and moisture transfer around single short porous cylinders during forced convection drying. The results arising out of their analysis of coupled heat and mass transfer were correlated in terms of Nusselt and Sherwood numbers. The correlation is used during the prediction of initial drying rates for short cylinders. The review of literature shows that no previous studies of jute fiber ropes as wetted media in the form of rope bank have been carried out. In this paper the performance of jute rope bank as wetted media is analyzed. These fibers are capable of retaining high moisture and have a large wetted surface area. AlSulaiman (2002). The prediction of heat and mass transfer coefficients is made by assuming the surface temperature of the ropes as WBT of incoming air. The factors like outlet temperature of air, saturating efficiency and cooling capacity of the cooler are estimated.

\section{Methodology}

\section{Arrangement of wetted media}

Fig. 1 shows the arrangement of the jute fiber rope bank inside the frame. The front area of the frame is 0.6 $\mathrm{m}$ by $0.6 \mathrm{~m}$ and its depth is equal to $0.3 \mathrm{~m}$. Top and bottom supports can keep the ropes vertically positioned. In general, staggered and compact banks achieve higher heat transfer rates when compared to in-line and widely spaced banks (Khan et al., 2006). Therefore staggered array is preferred for the analysis. The longitudinal pitch is equivalent to the diameter of ropes and the transverse pitch can be either 1.5 D (arrangement A) or $1.25 \mathrm{D}$ (arrangement B).

Fig. 2 shows the configuration of rope bank and Table 1 shows the geometrical parameters for two arrangements $A$ and $B$. The flow of water can be maintained on the upper side of the rope bank with the help of re-circulating pump that keeps the ropes wet. The cylindrical surface of each rope is considered as wetted surface and the total wetted surface area of the entire rope bank is given by following eqn.

$A_{w}=N \Pi D H \quad \mathrm{~m}^{2}$

Hot air as it comes in causes the evaporation of water at the rope surface giving rise to combined effects of heat and mass transfer.

\section{Velocity \& mass flow rate considerations}

The velocity of air at the entry point of the rope bank is allowed to vary between $0.75 \mathrm{~m} / \mathrm{s}$ and $2.25 \mathrm{~m} / \mathrm{s}$. This range is recommended not only in the literature that focuses on evaporative coolers but also by manufacturers (ECOCOOL evaporative cooling pad catalog from Arctic India P. Ltd. Gurgaon, India). These velocities are assumed to be uniform while entering the rope bank and are further enhanced by the restricted passage between the ropes. Mass flow rate of air is calculated on the basis of frontal area of the frame for the ropes, and density and velocity of air at the entry.

$M_{a}=\rho V_{a} H W \mathrm{~kg} / \mathrm{s}$

Heat \& mass transfer analogy

During the evaporation of water into air, low mass flux approximation involves a maximum error of $2.5 \%$ and
Research article

CIndian Society for Education and Environment (iSee)
"Jute for air-conditioning" http://www.indjst.org
Kulkarni \& Rajput Indian J.Sci.Technol. 
therefore heat mass convection analogy can be used (Cengel, 2004). Under these conditions determination of mass convection coefficients can be made by picking up the appropriate Nusselt number correlation for the given geometry and boundary conditions and replacing the Nusselt number with the Sherwood number and the Prandtl number by the Schmidt number (Cengel, 2004). As such, the results derived for the bank of tubes may be used for the determination of mass transfer rates specifically associated with the evaporation of water from the surfaces of bank of tubes in cross flow. Mass and heat transfer coefficients are calculated on the basis of standard relations and outlet temperature of air is calculated on the basis of empirical relation. The other related parameters are then calculated on the basis of psychrometric relations (2009).

Ambient conditions

The weather data of Bhopal on the basis of usually prevalent conditions in the month of April, May and part of June were collected and classified into five groups of average maximum dry bulb temperature (DBT) and relative humidity $(\mathrm{RH})$. These conditions are shown in Table 2. The most frequently occurring conditions of $39.9^{\circ} \mathrm{C} \mathrm{DBT}$ and $32.8 \% \mathrm{RH}$ are selected for the analysis. The corresponding wet bulb temperature (WBT) is also shown.

\section{Evaluation of air properties}

Correlations and non-dimensional numbers used in this analysis require the evaluation of properties of air. In the literature the properties are evaluated at the arithmetic mean of fluid inlet and outlet temperature (Cengel, 2004). In order to obtain more consistent results for convective transfer coefficients, there arises a need to evaluate physical properties of air at film temperature (Sun \& Marrero, 1996). In evaporative cooling, water is continuously re-circulated; therefore its temperature stabilizes close to what is ambient WBT (Liao \& Chiu, 2002). On this basis, surface temperature of the ropes is assumed to be equal to the WBT of incoming air and the properties of air are evaluated at film temperature that works out to be

$t_{f}=\frac{t_{1}+t_{s}}{2}=32.75^{\circ} \mathrm{C}$

All the properties of air are referred at this temperature barring those, which are to be referred at surface temperature. Density, kinematic viscosity and thermal diffusivity are corrected for altitude at Bhopal. Diffusion coefficient is calculated using the empirical formula.

$D_{A B}=1.87 \times 10^{-10}\left[\frac{T^{2.072}}{P}\right] \mathrm{m}^{2} / \mathrm{s}$.

Where $T$ is absolute temperature and $P$ is pressure in atm.

$$
\rho=1.094 \mathrm{~kg} / \mathrm{m}^{3} C_{p}=1007 \mathrm{~J} / \mathrm{kgK} \quad v=17.24 \times 10^{-6} \mathrm{~m}^{2} / \mathrm{s}
$$

$$
\begin{aligned}
& v_{s}=15.68 \times 10^{-6} \mathrm{~m}^{2} / \mathrm{s} \quad \alpha=2.369 \times 10^{-5} \mathrm{~m}^{2} / \mathrm{s} \\
& D_{A B}=2.784 \times 10^{-5} \mathrm{~m}^{2} / \mathrm{s} \quad\left(D_{A B}\right)_{s}=2.651 \times 10^{-5} \mathrm{~m}^{2} / \mathrm{s}
\end{aligned}
$$
Reynolds number

Reynolds number used in correlations is calculated on the basis of the maximum air velocity occurring in the rope bank that may occur either at transverse plane or diagonal plane for the staggered array. The condition for maximum velocity occurring at the diagonal plane is $2(S D-D)<(S T-D)$. However, this condition is not satisfied either by arrangement $A$ or $B$ and hence maximum velocity occurs at transverse plane and is given by the eqn.:

$V_{\max }=\left[\frac{S T}{S T-D}\right]\left(V_{a}\right)$

Reynolds number is given by the eqn.

$$
R e_{\text {Dmax }}=\frac{V_{\max } \times D}{v}
$$

\section{Lewis number and Schmidt number}

These numbers are based on diffusion coefficient of water into air and are calculated on the basis of the following relations:

$$
\begin{aligned}
& L e=\frac{\alpha}{D_{A B}} \\
& S c=\frac{v}{D_{A B}} \\
& (S c)_{s}=\frac{v_{s}}{\left(D_{A B}\right)_{s}}
\end{aligned}
$$

\section{Sherwood number}

The appropriate correlation for Nusselt number for staggered tube banks for $\left(\frac{S T}{S L}\right)<2$ and $\left(N_{L}\right)>16$ is chosen and Nusselt number is replaced by Sherwood number and Prandtl number is replaced by Schmidt number.

$S h_{D}=0.35\left(\frac{S T}{S L}\right)^{0.2} R e_{D \max }^{0.6}(S C)^{0.36}\left(\frac{S C}{(S C) s}\right)^{0.25}$

As $N_{L}=12$, in the present analysis, a correction factor of 0.985 is applied for Sherwood number. Hence,

$S h_{D N L=12}=0.985 \times S h_{D}$

\section{Heat \& mass transfer coefficients}

Mass transfer coefficient is based on Sherwood number and is given by the equation

$$
h_{m}=\frac{S h_{D N_{L}=12} D_{A B}}{D} \mathrm{~m} / \mathrm{s}
$$


Fig. 1. Arrangement of Jute rope bank.

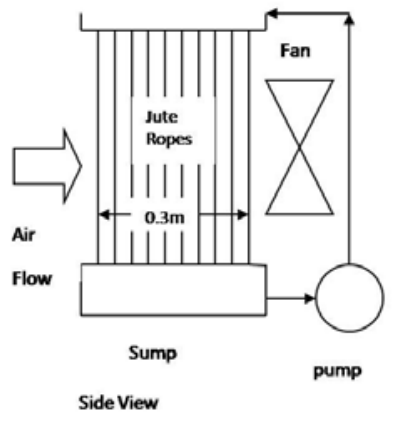

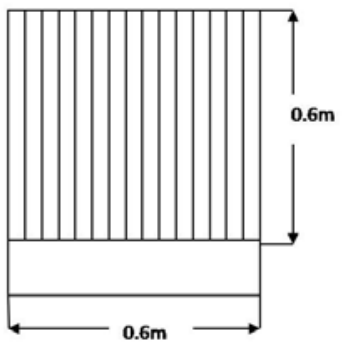

Front view

Vol. 3 No. 10 (Oct 2010)

ISSN: 0974- 6846

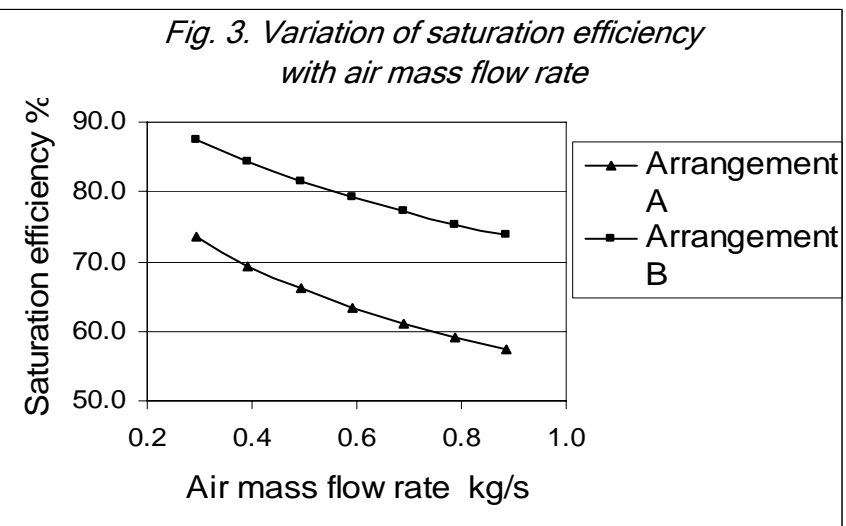

Fig. 2. Dimensions of jute rope bank (Top view).

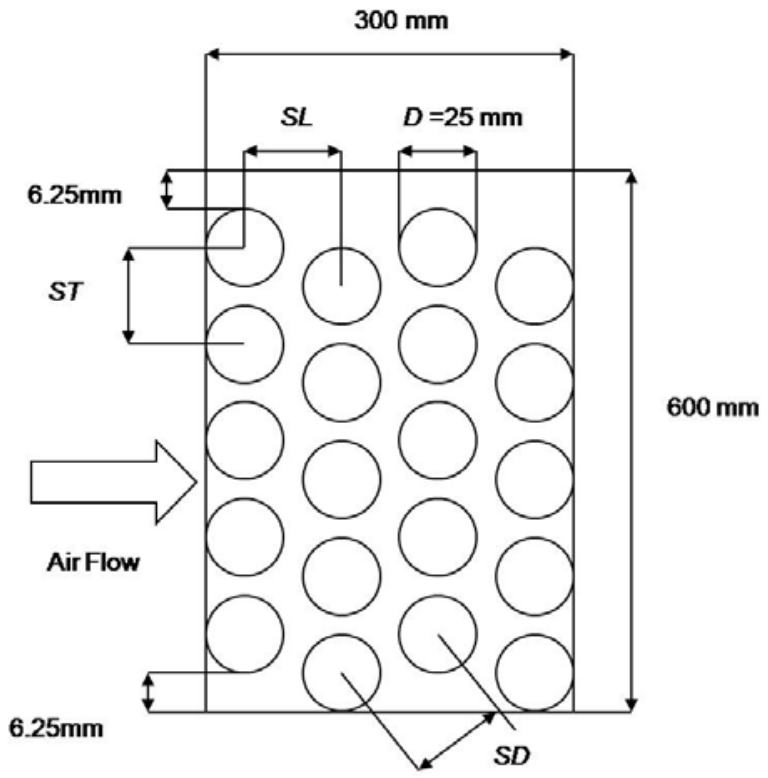

Fig. 5. Variation of pressure drop with air mass flow rate

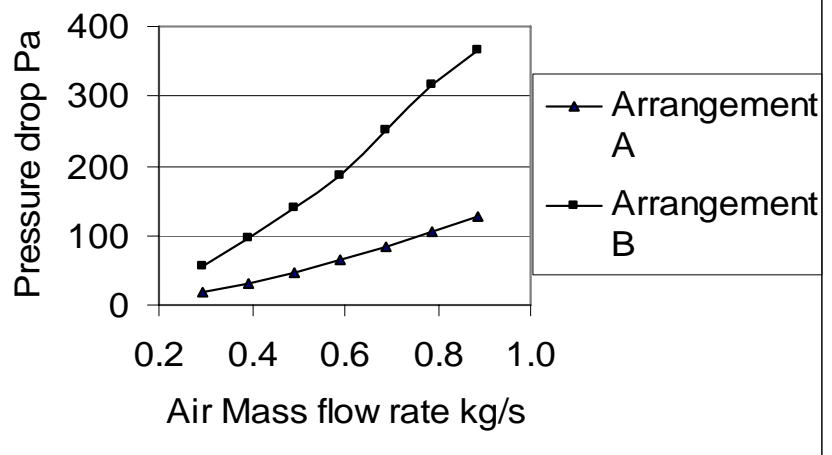

Fig. 4. Variation of cooling capacity with air mass flow rate

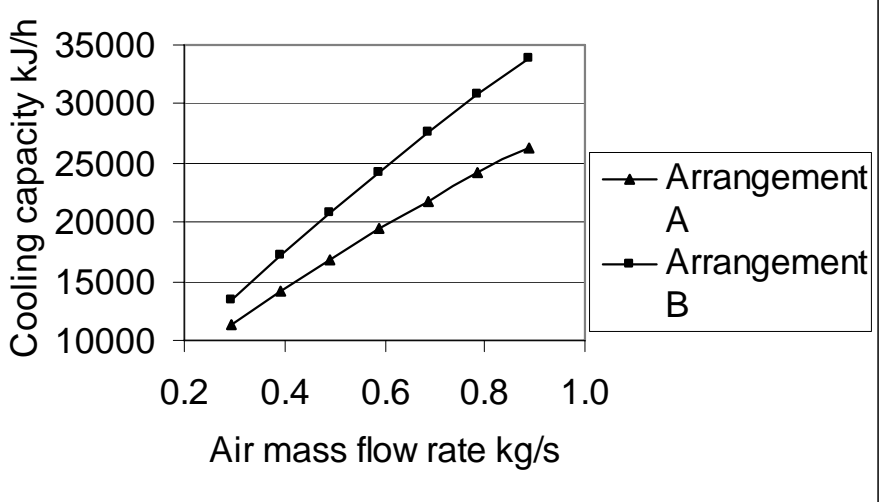

Heat transfer coefficient is calculated based on analogy between heat and mass transfer and which is given by the eqn:

$$
h_{c}=\rho C_{p} h_{m}\left(L_{e}\right)^{2 / 3} \quad \mathrm{~W} / \mathrm{m}^{2} \mathrm{~K}
$$

Fig. 6. Variation of fan power with air mass flow rate

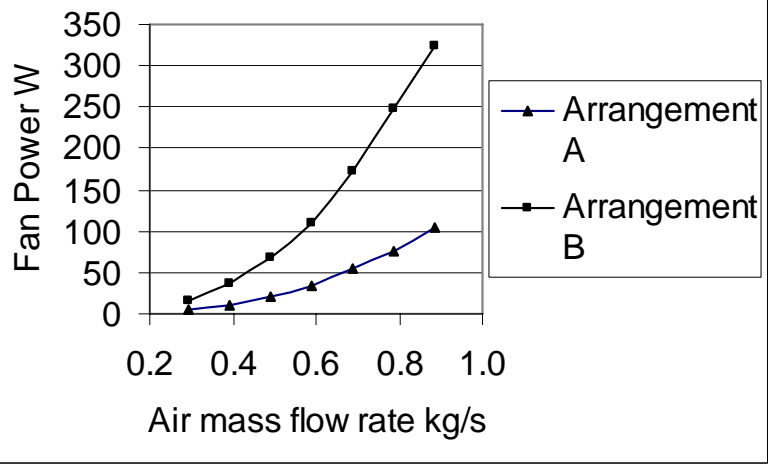

\section{Outlet air temperature}

The temperature of air at the outlet of rope bank can be predicted by measures of heat transfer coefficient, total wetted surface area and mass flow rate of air (Cengel, 2004). 
$t_{2}=t_{s}-\left(t_{s}-t_{1}\right) \exp \left[\frac{-A_{w} h_{c}}{M_{a} C_{p}}\right]{ }^{\circ} \mathrm{C}$

\section{Performance parameters}

Performance parameters such as saturating efficiency and cooling capacity can be calculated on the basis of outlet temperature of air and specific and relative humidity are calculated on the basis of psychrometric relations.

Saturation efficiency for such type of cooler can be calculated by the eqn.:

$\eta=\frac{t_{1}-t_{2}}{t_{1}-t_{w 1}}$

The cooling capacity is given by (Watt \& Brown, 1997)

$Q_{c}=M_{a} \times C_{p} \times\left(t_{1}-t_{2}\right) \times 3.6 \mathrm{~kJ} / \mathrm{h}$

\section{Pressure drop}

The pressure drop across the rope bank is determined by

$\Delta P=N_{L} \chi\left[\frac{(\rho)\left(V_{\max }\right)^{2}}{2}\right](f) \quad \mathrm{Pa}$

Standard graphs were used as reference for the friction factor and the correction factor.

\section{Fan power requirement}

A major component of the power required for evaporative cooler is the power required to move the air through the rope bank which is proportional to pressure drop and can be determined using the eqn.:

$P=V_{f} \Delta P \quad \mathrm{~J} / \mathrm{s}$

The various parameters that are calculated using the eqn. 1 through 16 are shown in Table 2 and 3.

\section{Results and discussions}

As expected the volume flow rate and mass flow rate of air increase with the velocity. The maximum velocity is 3 times the velocity at the entry in case of widely spaced arrangement $(\mathrm{A})$ and 5 times the initial velocity at the entry in case of compact arrangement (B). As Reynolds number is based on maximum velocity, its value increases from 3264-9791 in widely spaced arrangement. In contrast, in the case of compact arrangement, due to the more restricted passage between the ropes, maximum velocity has higher value and consequently Reynolds number increases from 5439 to 16318.

Sherwood number and mass transfer coefficient reflect effectiveness of mass convection at the rope surface. It is seen that with increasing velocity, mass convection occurs more effectively. Heat transfer coefficient depends on mass transfer coefficient and increases from 44.96 to $86.91 \mathrm{~W} / \mathrm{m}^{2} \mathrm{~K}$ in case of widely spaced rope bank arrangement. Considering that the maximum velocity values achieved are higher in compact arrangement, this arrangement gives higher heat transfer coefficients ranging from $58.89 \mathrm{~W} / \mathrm{m}^{2} \mathrm{~K}$ to $113.85 \mathrm{~W} / \mathrm{m}^{2} \mathrm{~K}$. Higher heat transfer coefficients result in lower outlet temperature of air from $29.4^{\circ} \mathrm{C}$ to $27.4^{\circ} \mathrm{C}$ in compact arrangement when compared with $31.7^{\circ} \mathrm{C}$ to $29.4^{\circ} \mathrm{C}$ in widely spaced arrangement. Even when the heat transfer coefficients increase, the outlet temperature of air noticeably increases in both the arrangements due to Table 1. Geometrical parameters of jute rope bank

\begin{tabular}{|l|c|c|}
\hline Parameter & Arrangement A & Arrangement B \\
\hline$S T$ & $37.5 \mathrm{~mm}$ & $31.25 \mathrm{~mm}$ \\
\hline$S L$ & $25 \mathrm{~mm}$ & $25 \mathrm{~mm}$ \\
\hline$S D$ & $31.25 \mathrm{~mm}$ & $29.5 \mathrm{~mm}$ \\
\hline No. of rows depth $N_{L}$ & 12 & 12 \\
\hline $\begin{array}{l}\text { No of ropes } \\
\text { In } 1^{\text {st }}, 3^{\mathrm{d}}, 5^{\text {th }} \ldots 11^{\text {th }} . \text { rows }\end{array}$ & 16 & 19 \\
\hline $\begin{array}{l}\text { No of ropes } \\
\text { In } 2^{\text {nd }}, 4^{\text {th }}, 6^{\text {th }} \ldots .12^{\text {th }} \text { rows }\end{array}$ & 15 & 18 \\
\hline Total No. of Ropes $N$ & 186 & 222 \\
\hline Total wetted surface area $A_{w}$ & $8.765 \mathrm{~m}^{2}$ & $10.46 \mathrm{~m}^{2}$ \\
\hline Approach velocity & $V_{a} \mathrm{~m} / \mathrm{s}$ & $V_{a} \mathrm{~m} / \mathrm{s}$ \\
\hline Maximum velocity $V_{\max }$ & $3 V_{a} \mathrm{~m} / \mathrm{s}$ & $5 V_{a} \mathrm{~m} / \mathrm{s}$ \\
\hline
\end{tabular}

higher mass flow rates associated with increased air velocity. Therefore saturation efficiency decreases with velocity. This is in accordance with other types of evaporative coolers that use different media with different configurations.

Fig. 3 shows variation of saturation efficiency with mass flow rate of air. It shows that saturation efficiency decreases from $73 \%$ to $57 \%$ and from $87 \%$ to $74 \%$ for widely spaced arrangement and compact arrangement respectively, corresponding to an increase in mass flow rate from 0.3 to $0.9 \mathrm{~kg} / \mathrm{s}$. In the experiments conducted by Al-Sulaiman (2002) the cooling efficiency of jute fibers has been reported as $62.1 \%$ with air velocity of $2.4 \mathrm{~m} / \mathrm{s}$ and DBT of about $35^{\circ} \mathrm{C}$. Lower range of velocities and uniform wetting of surface assumed in the present analysis gives theoretically higher values of efficiency. Instead of keeping jute fibers loosely packed in a box, rope bank enables uniform exposure of cooled surface to air which in turn increases efficiency. Fig. 4 shows the variation of cooling capacity. As is evident from fig. the cooling capacity increases with mass flow as greater mass of air is being cooled. It increases from $11243 \mathrm{~kJ} / \mathrm{h}$ to $26381 \mathrm{~kJ} / \mathrm{h}$ and from $13384 \mathrm{~kJ} / \mathrm{h}$ to $33852 \mathrm{~kJ} / \mathrm{h}$ for widely spaced arrangement and compact arrangement respectively.

Fig. 5 and 6 show the variation of pressure drop and fan power with mass flow rate. As higher mass flows are a result of higher velocities, both pressure drop and fan power increase in tandem with the mass flow rate. Pressure drop increases from $17.3 \mathrm{~Pa}$ to $128.6 \mathrm{~Pa}$ and from 55.4 $\mathrm{Pa}$ to $365.5 \mathrm{~Pa}$ for widely spaced and compact arrangement respectively. Fan power increases from 4.7 $\mathrm{W}$ to $104.2 \mathrm{~W}$ and from $16.4 \mathrm{~W}$ to $323.9 \mathrm{~W}$ for widely spaced and compact arrangement respectively.

It is seen that $14 \%$ increase in efficiency and marginal decrease of $2^{\circ} \mathrm{C}$ in outlet temperature are obtained with compact arrangement; however there is considerable increase in power consumption which is at least 3 times when compared to widely spaced arrangement. Hence
Research article

CIndian Society for Education and Environment (iSee)
"Jute for air-conditioning" http://www.indjst.org
Kulkarni \& Rajput Indian J.Sci.Technol. 
widely spaced arrangement is preferable to ensure substantial energy savings.

Table 2. Averaged weather data at Bhopal, India

\begin{tabular}{|c|c|c|c|c|c|}
\hline $\begin{array}{c}\text { Ambient } \\
\text { condition }\end{array}$ & $\begin{array}{c}\mathrm{DBT}_{\max } \\
{ }^{\circ} \mathrm{C}\end{array}$ & $\begin{array}{c}\text { Total } \\
\text { days }\end{array}$ & $\begin{array}{c}\text { Average } \\
\text { maximum } \\
\text { DBT }{ }^{\circ} \mathrm{C}\end{array}$ & $\begin{array}{c}\text { Average } \\
\mathrm{RH} \%\end{array}$ & $\begin{array}{c}\text { WBT } \\
{ }^{\circ} \mathrm{C}\end{array}$ \\
\hline $\mathrm{A}$ & Below $35^{\circ} \mathrm{C}$ & 5 & 33.8 & 39 & 22.58 \\
\hline $\mathrm{B}$ & $35-39^{\circ} \mathrm{C}$ & 10 & 37.1 & 34.5 & 23.98 \\
\hline $\mathrm{C}$ & $39-41^{\circ} \mathrm{C}$ & 29 & 39.9 & 32.8 & 25.59 \\
\hline $\mathrm{D}$ & $41-42^{\circ} \mathrm{C}$ & 18 & 41.4 & 26.1 & 24.63 \\
\hline $\mathrm{E}$ & Above $42^{\circ} \mathrm{C}$ & 5 & 42.6 & 22.6 & 24.28 \\
\hline
\end{tabular}

Table 3. Typical parameters for arrangement $A$

\begin{tabular}{|c|c|c|c|c|c|}
\hline$V_{a}$ & $\mathrm{~m} / \mathrm{s}$ & 0.75 & 1.25 & 1.75 & 2.25 \\
\hline$V_{\max }$ & $\mathrm{m} / \mathrm{s}$ & 2.25 & 3.75 & 5.25 & 6.75 \\
\hline$V f$ & $\mathrm{~m}^{3} / \mathrm{s}$ & 0.27 & 0.45 & 0.63 & 0.81 \\
\hline$M_{a}$ & $\mathrm{~kg} / \mathrm{s}$ & 0.295 & 0.492 & 0.689 & 0.886 \\
\hline$R e_{D \max }$ & & 3264 & 5439 & 7615 & 9791 \\
\hline Sc & & \multicolumn{4}{|c|}{0.6190} \\
\hline$(S c) s$ & & \multirow{2}{*}{\multicolumn{4}{|c|}{$\begin{array}{l}0.5913 \\
08509\end{array}$}} \\
\hline$L e$ & & & & & \\
\hline \multicolumn{2}{|c|}{$S h_{D N L}=12$} & 40.83 & 55.47 & 67.88 & 78.92 \\
\hline$h_{m}$ & $\mathrm{~m} / \mathrm{s}$ & 0.0455 & 0.0618 & 0.0756 & 0.0879 \\
\hline$h_{c}$ & $\mathrm{~W} / \mathrm{m}^{2} \mathrm{~K}$ & 44.96 & 61.08 & 74.74 & 86.91 \\
\hline$t_{2}$ & ${ }^{\circ} \mathrm{C}$ & 29.40 & 30.45 & 31.16 & 31.69 \\
\hline$\eta$ & $\%$ & 73.4 & 66.1 & 61.1 & 57.4 \\
\hline$\omega_{o}$ & $\begin{array}{l}\mathrm{kg} / \mathrm{kg} \\
\text { dry air }\end{array}$ & 0.02061 & 0.02016 & 0.01986 & 0.01963 \\
\hline$R H$ & $\%$ & 74.4 & 68.6 & 64.9 & 62.3 \\
\hline$Q_{c}$ & $\mathrm{~kJ} / \mathrm{h}$ & 11243 & 16857 & 21832 & 26381 \\
\hline$f$ & & 0.52 & 0.49 & 0.47 & 0.43 \\
\hline$\chi$ & & \multicolumn{4}{|c|}{ 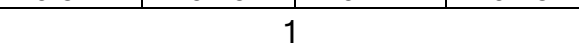 } \\
\hline$\Delta P$ & $\mathrm{~Pa}$ & 17.28 & 45.23 & 85.03 & 128.60 \\
\hline$P$ & W & 4.67 & 20.35 & 53.57 & 104.17 \\
\hline
\end{tabular}

\section{Conclusions}

Jute fibers have high moisture retention capacity and can be used as wetted media for evaporative coolers. Their performance when used as rope bank across the flow of air has been theoretically analyzed. In this arrangement, the evaporation of water on surface of ropes reduces the dry bulb temperature of air and involves simultaneous heat and mass transfer. The required air properties are evaluated at film temperature by assuming the surface temperature of ropes to be WBT of incoming air. Mass and heat transfer coefficients are calculated on the basis of empirical correlations and outlet temperature of air is predicted as well, and in turn, on the basis of outlet temperature, saturation efficiency and cooling capacity of the cooler are also calculated. Saturation efficiency of such cooler is theoretically found to be in the range of $57 \%$ to $73 \%$ and $74 \%$ to $87 \%$ for widely spaced bank and compact bank respectively for air mass flow rates between 0.9 and $0.3 \mathrm{~kg} / \mathrm{s}$. The outlet temperature of air ranges between $27.4^{\circ} \mathrm{C}$ and $31.7^{\circ} \mathrm{C}$ for ambient condition of $39.9^{\circ} \mathrm{C}$ and $32.8 \% \mathrm{RH}$.

Compact arrangement gives higher saturation efficiency and lower outlet temperature of air at the cost of higher power consumption. Hence, findings lead to the conclusion that widely spaced arrangement is a better way to save the energy with relatively little sacrifice in comfort. However this is possible only when jute fibers are available at cheaper rate. The jute fibers, when treated appropriately, to offer higher resistance to mold forming, can be used as alternative media in this form for evaporative coolers.

Table 4. Typical parameters for arrangement $B$

\begin{tabular}{|c|c|c|c|c|c|}
\hline$V_{\max }$ & $\mathrm{m} / \mathrm{s}$ & 3.75 & 6.25 & 8.75 & 11.25 \\
\hline$V f$ & $\mathrm{~m}^{3} / \mathrm{s}$ & 0.27 & 0.45 & 0.63 & 0.81 \\
\hline$M_{a}$ & $\mathrm{~kg} / \mathrm{s}$ & 0.295 & 0.492 & 0.689 & 0.886 \\
\hline$R e_{D \max }$ & & 5439 & 9066 & 12692 & 16318 \\
\hline Sc & & \multicolumn{4}{|c|}{0.6190} \\
\hline$(S c) s$ & & \multirow{2}{*}{\multicolumn{4}{|c|}{$\begin{array}{l}0.5913 \\
0.8509\end{array}$}} \\
\hline$L e$ & & & & & \\
\hline \multicolumn{2}{|c|}{$S h_{D N L}=12$} & & 72.66 & 88.92 & 103.39 \\
\hline$h_{m}$ & $\mathrm{~m} / \mathrm{s}$ & 0.0596 & 0.0809 & 0.0990 & 0.1151 \\
\hline$h_{c}$ & $\mathrm{~W} / \mathrm{m}^{2} \mathrm{~K}$ & 58.89 & 80.01 & 97.91 & 113.85 \\
\hline$t_{2}$ & ${ }^{\circ} \mathrm{C}$ & 27.40 & 28.24 & 28.87 & 29.36 \\
\hline$\eta$ & $\%$ & 87.4 & 81.5 & 77.2 & 73.7 \\
\hline$\omega_{o}$ & $\begin{array}{l}\mathrm{kg} / \mathrm{kg} \\
\text { dry air }\end{array}$ & 0.02146 & 0.0211 & 0.02083 & 0.02063 \\
\hline$R H$ & $\%$ & 86.9 & 81.4 & 77.5 & 74.6 \\
\hline$Q_{c}$ & $\mathrm{~kJ} / \mathrm{h}$ & 13384 & 20808 & 27567 & 33852 \\
\hline$f$ & & 0.6 & 0.54 & 0.5 & 0.44 \\
\hline$\chi$ & & \multicolumn{4}{|c|}{1} \\
\hline$\Delta P$ & $\mathrm{~Pa}$ & 55.38 & 138.46 & 251.28 & 365.53 \\
\hline$P$ & $\mathrm{~W}$ & 16.36 & 68.16 & 173.18 & 323.91 \\
\hline
\end{tabular}

\section{References}

1. Al-Sulaiman F (2002) Evaluation of the performance of local fibers in evaporative cooling. Energy Conversion Management. 43(16), 2267-2273.

2. Bhopal weather data (2008) Retrieved Nov 5. from www.tutiempo.net /en.

3. Camrago JR, Ebinuma CD and Siveria JL (2004) Experimental performance of a direct evaporative cooler operating during summer in Brazilian city. Int. J. Refrigeration. 28(7), 1124-1132.

4. Cengel YA (2004) Heat transfer: A practical approach. $2^{\text {nd }} \mathrm{SI}$ edn. Tata Mc-Graw Hill, New Delhi.

5. Gomez EV, Rey Martinez FJ, Varela Diez F, Molina Leyva MJ and Herrero Martin R (2005) Description and experimental results of a semi-indirect ceramic evaporative cooler. Int. J. Refrigeration. 28(5), 654-662.

6. Khan WA, Culham JR and Yovanovich MM (2006) Convection heat transfer from tube banks in cross flow: Analytical approach. Int. J. Heat Mass Transfer. 49(25-26), 4831-4838.

7. Liao C and Chiu K (2002) Wind tunnel modeling the system performance of alternative evaporative cooling pads in Taiwan region. Building Environ. 37(2), 177-187.

8. Maheshwari GP, Al-Ragom F and Suri RK (2001) Energy saving potential of an indirect evaporative cooler. Appl. Energy. 69(1), 69-76.

9. Psychrometric properties calculator (2009) Retrieved Feb 5 from http://www.sugartech.co.za.

10. Sun SH and Marrero TR (1996) Experimental study of simultaneous heat and moisture transfer around single short porous cylinders during convection drying by a psychrometry method. Int. J. Heat Mass Transfer. 39(17), 3559-3565.

11. Watt JR and Brown WK (1997) Evaporative air conditioning handbook, $3^{\text {rd }}$ edn. The Fairmont press, Inc., Lilburn. 